\title{
TEXTUAL NOTES
}

Throughout the text I refer to the subject as Robert Duncan, though at various points his legal name was Edward Howe Duncan, Robert Edward Symmes, and Robert Edward Duncan. Duncan's companion Jess Collins is referred to by his chosen name, Jess.

A note on Duncan's spelling: in letters to friends, journal entries, and poems, Duncan often dropped the $e$ from past-tense verbs ("learnd") or shortened common words ("though" to "tho" or "could" to "cld"). Two of Duncan's early mentors, Ezra Pound and Jaime de Angulo, also used abbreviation and disregarded spelling conventions in their correspondence. Duncan may have inherited this idiosyncrasy when he worked as de Angulo's secretary. In poems, Duncan's omission of the $e$ from the past tense was a metrical cue, indicating the syllable count ("learnd," one syllable; "learned," two syllables). The quotes herein preserve all such spellings and eschew the use of $[$ sic] in the interest of preserving Duncan's style.

Several texts preceding the publication of this volume also provide important information about Robert Duncan's life and work. Ekbert Faas's Young Robert Duncan gives a view into Duncan's early life (1919-52). I have in this biography noted points at which Faas's information was incorrect as well as points at which the reader may want to refer to Faas for more detailed information. Kevin Killian and Lewis Ellingham's biography of Jack Spicer, Poet 
Be Like God, includes a good deal of information about Duncan's relationship with Spicer and about the larger constellations of community around the Berkeley and San Francisco Renaissance. Michael Davidson's The San Francisco Renaissance: Poetics and Community at Mid-Century, Ghostlier Demarcations: Modern Poetry and the Material Word, and Guys Like Us: Citing Masculinity in Cold War Poetics are all important works. Two of my peers, Devin Johnston and Peter O'Leary, have written books that also explore Duncan's work from a critical angle: Johnston's Precipitations and O'Leary's Gnostic Contagion.

While I have attempted here to give readers a good view into the source materials and personal circumstances surrounding Duncan's poems, I have refrained from deeper interpretations of the work in my interest to shape the book as biography rather than criticism. This book is the culmination of almost twenty-five years of research. I hope that my work will open the gate to a deeper understanding of Duncan's life and poetry and his relationships with the writers and artists whose work intersected with his. 